\title{
Research on the Current Situation and Countermeasures of Kindergarten Reading Education in Shenyang
}

\author{
Lina Zhang ${ }^{1, a}$, Xiaodong Pan ${ }^{1, b}$ and Zidong Wang ${ }^{2, c}$ \\ ${ }^{1}$ Teachers' College Shenyang University, Shenyang, China \\ ${ }^{2}$ Huaiying Kindergarten Chaoyang, Liaoning, China
}

Keywords: Early reading; early reading education; reading education in kindergartens

\begin{abstract}
Currently, reading education has been popular in kindergartens. However, some problems have gradually appeared along with the development of reading education. The current situation of kindergarten reading education in Shenyang was analyzed and studied through sampling survey method in this paper, and the existing problems are as follows: inadequate understanding with the target, not comprehensive consideration about the material selection, not enough attention to the environment creation, lacking the master of education methods and instruction and interaction with parents. Aiming at the above problems, the development of infants' reading abilities can be promoted by correctly understanding the target, selecting appropriate picture books, creating comfortable and harmonious reading atmosphere, mobilizing parents to participate in the related activities and paying attention to the scientific instruction of infants' reading.
\end{abstract}

\section{Definition of Related Concepts}

\subsection{Reading}

Reading means an activity that people can acquire the information through their understanding, absorption, appreciation, assessment and research with essays, sentences and words, which can help them objectively watch the world, learn knowledge, develop thought and feel the emotional pouring. [1]

\subsection{Reading education in kindergartens}

Reading education in kindergartens refers to all the related activities with infants' reading in the kindergarten, including the selected education material according to their development characteristics and relevant environment needed in the reading education.

\section{The Survey of Current Situation of The Kindergarten Reading Education in Shenyang}

\subsection{Survey design}

\subsubsection{Survey objective}

This paper was to survey and research the current situation and existing problems of kindergarten reading education in Shenyang, and to propose corresponding suggestions for the promotion of infants' reading abilities.

\subsubsection{Respondents}

Eleven kindergartens in Shenyang were selected for this research, among which there are three private international large-scale kindergartens, four private small and medium kindergartens and four public kindergartens.

\subsubsection{Survey content}

This paper mainly researched the current situation and problems of kindergarten reading education in Shenyang in the combination with teachers' teaching, from the aspects of related targets, content, environment, connection with other fields and combination with family education.

\subsubsection{Survey methods}

Sampling survey method was mainly adopted in this paper to raise the existing problems. And the teachers' teaching plans and infants' reading materials were sampled. 


\subsection{Analysis of current situation of kindergarten reading education in Shenyang}

\subsubsection{Current situation analysis of early reading education targets}

Based on the requirement of reading experience raised in Core Experience of Preschool Children's Language Learning and Development, the related target implementation conditions of these eleven kindergartens can be divided into three kinds. First, the cultivation of good reading habits and behavior. Infants can have autonomous and quiet reading under teachers' guidance, which accounted for about 38.1\%. Second, the training of reading abilities. Infants can read the characters in the books, which accounted for $100 \%$. Third, the expression and assessment of reading content. Infants have the courage to retell the story plots before classmates, which accounted for about $60.71 \%$.

Obviously, teachers usually pay attention to the development of reading abilities when designing education activities. But the experience of the cultivation of reading habits and behavior only was noticed by about $38 \%$ of the teachers.

\subsubsection{Current situation analysis of early reading education content}

Eighty-five teaching plans were selected in this paper, and seventy-three picture books were involved, among which there were sixteen domestic ones, about $22 \%$ and the others were foreign ones. And most of foreign picture books were repeated for use. The topic of picture books can be divided into six kinds according to the teaching targets of education activities, including twenty-three about emotion, seventeen about self-awareness, thirteen about quality training, fourteen about knowledge imparting, five about habits training and thirteen about entertainment. The number of the first two kinds was rather large. If divided from the genre, there were seventy about story, nine about science knowledge and only six about poetry and prose.

As can be seen, foreign picture books were selected more, and the theme of emotion and the genre of story were preferred. Meanwhile, the education functions of picture books were approved by all teachers.

2.2.3 Current situation analysis of early reading education environment

The environment of early reading education in the kindergarten is one significant factor affecting infants' reading. In the eleven kindergartens in this paper, there was eight having specific reading areas, two having books in the autonomous activity areas and another one only having one bookshelf for infants to get book and back their small chairs for reading. All of these showed that most kindergartens have launched reading corners and create beneficial environment for infants' reading. As for reading time, reading education activity was arranged in class in seven kindergartens, by teachers' allocation in two and arranged in infants' free activities. So, early reading education in kindergartens has absorbed the increasing attention of most kindergartens.

\subsubsection{Current situation analysis of the combination of early reading and field education}

The analysis of four hundred and sixteen reading education teaching plans in these eleven kindergartens showed that there were sixty-seven only involving the field of language, about $16 \%$, two hundred and fifty-three combining with the field of language and society, about $61 \%$, forty-three involving the field of language and science, about $10 \%$, twenty-nine combining with the field of language and health, about $7 \%$ and twenty-four involving the field of language and art, about $6 \%$. The research result showed that the integration of teaching modes was applied to $80 \%$ of the teaching activities. So, the number of teachers who have realized the coherence of five great fields is increasing and they have applied this pattern to the practical teaching activities.

2.2.5 Current situation analysis of the combination of early reading and family education

According to the statistics of related literature material, the quantity of infants' reading material in Shenyang was enough. There were $18.8 \%$ of the infants possessing more than fifty books and $75.7 \%$ having twenty to fifty. And there hardly existed the phenomenon that infants have no reading material. In the top class of kindergarten, about $63 \%$ of the parents put the purchase of books about intelligence in the first place and about knowledge second. The selection of books about story was very little, only 3.7\%. So, parents didn't have enough understanding with infants' reading education concepts. 


\section{Analysis of Kindergarten Reading Education in Shenyang}

\subsection{Distort the target of early reading education}

Early reading target means to the basic ability of reading comprehension, desire to write essays and elementary skills. The core is to understand the reading content and form reading strategies, namely, understand the meaning of characters based on literacy, learn to experience the emotional change of characters, feel their qualities and characters and the difference between others and ourselves. So, early reading is not equal to early literacy. The two have great difference, and it is wrong to only regard literacy as the promotion of reading abilities.

\subsection{Select the reading materials not appropriate for infants}

The above survey showed that eighty-five teaching plans involved seventy-three different picture books and six different themes, mainly oriented with the genre of story. There were rather few books about science, knowledge, poetry and prose. At the same time, many picture books were too old to absorb infants, and boring content couldn't give full play to the ideal effect in the reading education. In addition, there existed some problems in the selection of foreign picture books, for example, the plots in the picture books were not completely identical with Chinese infants' experience in the daily life, and some teaching methods of common knowledge had great difference with our education, which should arouse teachers' consideration.

\subsection{Ignore the creation of mental environment of reading}

In the kindergarten teaching, infants are the subjects of study. In the establishment of environment, infants' development demands should be considered to connect their characteristics with environment. At the same time, infants' interest should be considered to inspire their enthusiasm with reading and produce the reading impetus so as to read actively and form reading habits. It can be found in the visit process that there were seven kindergartens that didn't express the subject status of infants in the establishment of reading regional environment and the boring arrangement cannot fully mobilize infants' reading positiveness. Besides, the feature of education of reading environment wasn't presented.

\subsection{Lack the scientific guidance of infants' reading}

Preschool teachers usually apply the reciting method to teach infants in reading education, which means that infants read after the teacher and then read by themselves when they are familiar with the content. Such method is so boring and single that infants will be easy to lose interests. If teachers use the method of questions and answers to highlight infants to imagine and retell them in combination with infants' experience, it will be easy for infants to accept. While such method requires the teacher to raise questions according to infants' thought development characteristics and make positive feedbacks with infants' answers. Pure questions without any enlightening meaning will fail to realize the target of reading activity.

\subsection{Lack the real communication with parents}

Parents' enthusiasm with infants' literacy ignores the characteristics of their development and distorts the meaning of early reading, which is easy for infants to produce the emotion of boredom and resistance and then causes the loss of early reading education. In order to avoid such phenomenon, preschool teachers should give play to the function of family cooperation and often communicate with parents to give them timely guidance and share reading content and methods, which will help infants mobilize their reading interest to a largest degree and achieve the target of reading education together.

\section{Basic Countermeasures of Kindergarten Reading Education in Shenyang}

\subsection{Correctly understand the targets of reading education}

Correctly understand the targets of early reading education are the first step. It is not early literacy education. The target consists of three aspects: first, train infants' reading interest and make them understand the meaning of words through the provision of proper environment and materials; second, let infants are familiar with characters and able to distinguish them and gradually know them in this process; third, gradually lead infants' unconscious graffiti to the conscious writing. These methods can help the cultivation of infants' reading interest at the early age and formation of good reading habits. 


\subsection{Select appropriate picture books for infants}

In the early reading, teachers should scientifically select appropriate picture books for infants according to their age development characteristics and awareness degree. And they need to guide infants to have autonomous reading and enjoy the free exploration and experience of the unknown world to inspire their reading desire. As for the book category, it should be made the diversified selection and cannot be confined to the single type like story books, but adding the poetry, prose, science and knowledge. And the book content shouldn't get away from infants' life. In terms of the pattern, aesthetic education should be considered, which means selecting those with proper characters number and the ability to inspire infants' imagination.

\subsection{Create comfortable and harmonious reading atmosphere}

Comfortable and harmonious mental environment can relax infants' inner heart to obtain better reading results. The related reading area should be launched in the quiet place where infants are offered free choice and reading and they can carefully read and form good reading habits. Besides, teachers should often encourage and praise infants and give them positive indications to mobilize their autonomous positiveness and keep reading interest and enthusiasm.

\subsection{Pay attention to the scientific instruction of infants' reading}

Teachers should give full play to education in the reading activity, adopting scientific and reasonable teaching methods to instruct infants and interact with them. Teachers are supposed to guide infants to independently think and encourage them to bravely express their thoughts with reading content, retell the understanding content and imagined plots to promote their innovation and overall development. In addition, teachers are supposed to be examples of infants to read and form good independent reading habits.

\subsection{Mobilize the parents to participate in the reading education activities}

Besides the efforts of teachers, reading education also needs parents' support and assistance. Kindergartens should also strengthen the family training, appropriately increase school days and teachers' home visit to enhance parents' awareness with early reading education, supervise infants' reading and help infants form good reading behavior and habits together with parents for infants' better overall development.

\section{Conclusion}

Early reading education in the kindergarten is significant to infants' future development. It can be found from the current situation of kindergarten reading education in Shenyang that the basic direction of kindergarten teachers on reading education is correct, but the related instruction behaviors still have some problems. After the conclusion and analysis, the literature method was introduced to solve the problem, namely, the basic countermeasures of "correctly understanding the target", "selecting appropriate picture books", "creating comfortable and harmonious reading atmosphere", "paying attention to the scientific instruction of infants' reading” and "mobilizing parents to participate in the related activities”.

\section{References}

[1]. Deng Mei. Related research on the literacy awareness development level and reading abilities of infants in top class[D]. Tianjin Normal University, Tianjin, 2017.5.

[2]. Zhang Ning. Research on the effects of sharing and communication on parents' instruction behavior in the early parent-child reading[D]. Hebei Normal University, Shijiangzhuang, 2016.6.28.

[3]. Wei Jihua. Research on the relation of reading comprehension abilities, reading attitudes and family reading environment of infants in top class[D]. East China Normal University, Shanghai, 2016.4.

[4]. Zou Qunxia. Research and analysis of current situation of early reading education in kindergartens[J]. Infant education, 2014, 15, 27-32.

[5]. He Dongyun. Research on the instruction behavior on early reading of preschool teachers[D]. Huaibei Normal University, Huaibei, 2017.5. 